\title{
PLÁGIO: IMPACTO NA FORMAÇÃO ACADÊMICA DOS GRADUANDOS EM ENGENHARIA DE MINAS - UFOP
}

\author{
Paulo Henrique Liberato da Silva-paulo.liberato@aluno.ufop.edu.br \\ Universidade Federal de Ouro Preto \\ Morro do Cruzeiro, s/n, Campus UFOP, Bauxita \\ 35400-000 - Ouro Preto - Minas Gerais
}

Guilherme Henrique Gualandi Rodrigues - guilhermegualandi@hotmail.com

Thiago Duarte Figueiredo - thiagoduarte1926@hotmail.com

Francielle Câmara Nogueira - franciellenoguera@yahoo.com.br

Carlos Alberto Pereira - pereiraufop@gmail.com

Resumo: O presente artigo teve como objetivo descrever o impacto do plágio nas atividades desenvolvidas no Departamento de Engenharia de Minas da Universidade Federal de Ouro Preto. Para tanto, foi realizada uma pesquisa que contou com a participação dos corpos discente e docente do curso. As respostas obtidas confirmaram que a prática do plágio por parte dos alunos é induzida principalmente pelo desconhecimento das normas institucionais, pelo descontentamento com os métodos de ensino e pela insegurança em realizar atividades por conta própria. Foi possível observar que a impunidade com quem realiza o plágio, associada à falta de conhecimento do estatuto por parte dos professores, e a escassez de medidas de conscientização pela universidade fomentam a prática do plágio. Como forma de controle dessa prática, foram propostas medidas como a orientação do corpo discente e docente sobre o tema e a discussão sobre plágio em todas as disciplinas. Além disso, faz-se importante a divulgação e aplicação rigorosa das regulamentações estabelecidas pelo Código de Convivência Discente por todos os professores.

Palavras-chave: Plágio. Formação acadêmica. Educação. Escrita científica.

\section{INTRODUÇÃO}

Atualmente, uma das grandes preocupações das instituições de ensino e pesquisa está relacionada à importância de promover a ética na execução trabalhos e na publicação de pesquisas científicas, uma vez que é cada vez mais comum que os membros das Instituições de Ensino Superior (IES) apropriem-se de conhecimentos ou de ideias já publicados sem a devida identificação dos autores, configurando, dessa maneira, o plágio acadêmico.

O plágio foi definido pela Fundação de Amparo à Pesquisa do Estado de São Paulo como "a utilização de ideias ou formulações verbais, orais ou escritas, de outrem sem dar-lhe por elas, expressa e claramente, o devido crédito, de modo a gerar razoavelmente a percepção de que sejam ideias ou formulações de autoria própria" (FAPESP, 2011). Existem diferentes tipos de plágio, entre os quais se destacam: o plágio integral, que consiste na cópia completa de trechos de uma determinada obra sem a devida referência; o plágio parcial, quando o autor transcreve partes de textos ou parágrafos de diversos autores, também sem referenciá-los; o plágio 
conceitual que ocorre quando a pessoa apropria-se de alguma ideia ou teoria de terceiros, transcrevendo-as de outra forma, no entanto, sem dar créditos à referência original. Também existe o autoplágio, que diz respeito à divulgação de resultados ou textos como inéditos, sendo que os mesmos já foram publicados anteriormente pelo próprio autor, sem explicitar a obra prévia (GIMENEZ et al., 2015).

Independentemente do tipo de plágio, esta é uma prática que vem crescendo atualmente, devido à facilidade de acesso a uma infinidade de informações disponíveis na rede. De acordo com Grego (2014), o conteúdo digital produzido no mundo dobra a cada dois anos. Seguindo a mesma tendência, o meio acadêmico também foi fortemente tocado pelas transformações digitais ocorridas nas últimas décadas, em que o ato de "pesquisar" e encontrar informações tornou-se mais simples e intuitivo. Mas, no meio acadêmico, se, por um lado, os avanços na tecnologia de informação aumentaram o acesso à informação, por outro lado, todo material produzido como monografias, dissertações, teses, artigos ganharam ampla visibilidade (COSTA, 2016).

Entretanto, o modelo de ensino e proteção de conteúdo não se desenvolveu com a mesma velocidade da globalização. Uma importante questão levantada por Costa (2016) é a falta de mecanismos por parte das instituições de ensino em monitorar toda a produção científica publicada e garantir os direitos autorais, violados com facilidade. Para entender como o curso de Engenharia de Minas da Universidade Federal de Ouro Preto tem adotado políticas de conscientização e informação sobre o plágio, desenvolveu-se este artigo que tem como objetivo compreender a prática do plágio nas atividades desenvolvidas no Departamento.

\section{METODOLOGIA}

Para realização desta pesquisa, foi elaborado um questionário, enviado via e-mail aos 17 professores que compõem o quadro de docentes do curso de Engenharia de Minas, e via link de aplicativo Whatsapp para os alunos do curso. O questionário foi elaborado com o auxílio do aplicativo de administração de pesquisas Google Forms e ficou disponível durante sete dias. Foram elaboradas 12 questões de múltipla escolha e 2 questões discursivas no questionário direcionado aos alunos e 8 questões de múltipla escolha e uma discursiva no questionário direcionado aos professores. Incorporar questões discursivas ao questionário permite que os entrevistados opinem, o que agrega diferentes perspectivas a respeito do tema.

A análise das respostas discursivas foi realizada a partir do método do Discurso do Sujeito Coletivo (DSC). Esta técnica de organização de dados consiste no agrupamento de informações semelhantes obtidas a partir de um conjunto de diferentes discursos coletados. Nesta pesquisa, as principais ideias encontradas na maioria das respostas dos professores e dos alunos foram agregadas em discursos-síntese que representaram a opinião dos participantes de forma unificada.

Além do questionário, foi realizado um levantamento junto à UFOP a respeito dos programas e iniciativas implantadas pela universidade para conscientizar e punir os casos de plágio identificados.

\section{RESULTADOS E DISCUSSÃO}

A prática do plágio durante a vida acadêmica pode gerar profissionais mal formados e despreparados para atuar com a ética e a qualidade que a carreira exige, prejudicando diretamente a sociedade. Ao longo do período acadêmico, o estudante que comete o plágio se 
baseia em apenas copiar, não exercitando sua escrita e criatividade, limitando seu desenvolvimento de raciocínio e sua capacidade de expressão textual.

Dias e Eisenberg (2013) discutem a importância em conduzir alunos e pesquisadores a refletirem questões éticas sob seus atos, mostrando-lhes que a prática de pequenas atitudes erradas a fim de gerar vantagens próprias tornam-se hábitos que podem repercutir ao longo de suas carreiras. Nesse ponto, destaca-se o papel da universidade, que, além da capacitação técnica do aluno, tem como função preparar indivíduos que irão servir eticamente a sociedade em prol do bem comum. Dessa forma, é importante que, ao longo de sua vida acadêmica, o estudante seja moldado para agir com retidão, honestidade e discernimento.

No meio acadêmico, o plágio pode acarretar em prejuízos consideráveis na vida de pesquisadores, que podem sofrer penalizações judiciais, profissionais e pessoais, difamando sua imagem e prejudicando sua carreira de forma, muitas vezes, irreversível. Em 2007, na Universidade de São Paulo (USP), por exemplo, o diretor do Instituto de Física foi acusado de liderar uma pesquisa que plagiou um então professor sênior, do Instituto de Estudos Avançados da própria universidade. Já em 2011, um docente da USP de Ribeirão Preto foi acusado de plágio, no caso, um professor pesquisador da área farmacêutica. Em ambos os casos os plagiadores, mesmo se tratando de pessoas reconhecidas no cenário acadêmico, foram punidos severamente, submetidos a moções éticas e até afastamento das atividades.

\subsection{Análise dos professores}

A pesquisa realizada neste artigo contou com a participação de 55,6\% dos docentes do Departamento de Engenharia de Minas da UFOP. Dos professores entrevistados, $100 \%$ relatam que já detectaram plágio em relatórios e seminários feitos pelos alunos. Questionados sobre a quantidade de alunos que cometem plágio nessas atividades (Tabela 1), 50\% dos docentes afirmaram que, em média, 60 a $80 \%$ dos discentes cometem plágio.

Tabela 1 - Índice de alunos que cometem plágio em relatórios e seminários

\begin{tabular}{cc}
\hline Professores $(\%)$ & Média de alunos que cometem plágio $(\%)$ \\
\hline 0 & $>80$ \\
50 & 60 a 80 \\
12,5 & 40 a 60 \\
25 & 20 a 40 \\
12,5 & 10 a 20 \\
0 & $<10$ \\
\hline & Fonte: Elaboração própria
\end{tabular}

Embora o índice de plágio relatado pelos professores consultados seja alto, na mesma pesquisa, 94,1\% dos alunos afirmam utilizar as normas de citação e referência durante a execução de trabalhos e seminários. Considerando o fato de que todos os discentes consultados afirmaram saber o que é plágio, esta contradição pode estar relacionada a uma possível interpretação incorreta dos alunos sobre o conceito de plágio e as formas corretas de referenciamento e utilização de citações de outros autores. Ações desse tipo caracterizam a prática do plágio involuntário, na qual o aluno utiliza conteúdos de outros autores e, sem intenção, não credita de maneira correta as informações utilizadas.

O elevado índice de plágio nos trabalhos acadêmicos no ensino superior também pode ser atribuído à ineficiência do modelo de ensino para crianças e adolescentes, que estimula a cópia para realização de atividades tanto no ensino fundamental quanto no ensino médio. 
Barbastefano e Souza (2007) evidenciaram a importância de trabalhar com os alunos, desde os anos iniciais, atividades de pesquisa sobre temas diversos, discutir sobre os assuntos, em vez de simplesmente copiar o material de sua fonte. Dessa maneira, durante a vida acadêmica do aluno, a cópia deixará de ser um hábito comum.

Além das medidas tomadas pelos professores até o ensino médio, é fundamental que os docentes de ensino superior estimulem o aluno a escrever, a expor suas ideias e a fundamentálas. Dias e Eisenberg (2013) exprimem a importância do estímulo que o professor deve passar ao estudante para que esse possa refletir sobre o que aprende, de modo a ter condições de elaborar uma via para o aprendizado, tornando-se, aos poucos, autores de seus próprios textos. Para tanto, é imprescindível que o sistema educacional promova ao aluno o desenvolvimento de pensamentos e posicionamentos críticos, ou seja, faça com que o estudante entenda todo o conteúdo que lhe foi passado e conheça as normas de escrita científica e de citação.

Sendo assim, considerando o papel fundamental dos docentes na atuação frente ao plágio, a opinião dos mesmos a respeito do tema foi analisada pelo método DSC, o que forneceu três agrupamentos principais com soluções para a redução do plágio no Departamento de Engenharia de Minas da UFOP. O primeiro grupo de respostas apontou como forma de prevenir o plágio a orientação aos alunos, mediante o esclarecimento das consequências e dos malefícios que tal ação pode trazer. O segundo grupo, entretanto, sugeriu a aplicação de punições rigorosas aos alunos que forem pegos plagiando, reiterando a necessidade de todos os professores atuarem de forma uniforme. O terceiro, por fim, considerou a pesquisa aliada à composição de trabalhos escritos um fator relevante que pode contribuir para a redução do plágio, visto que, se o aluno é constantemente direcionado a seguir as normas de escrita desde o início do curso, o mesmo estará mais preparado ao longo dos períodos e, consequentemente, a incidência de plágio será reduzida.

\subsection{Análise dos alunos}

Nesta pesquisa, 28,73\% dos alunos matriculados no curso de Engenharia de Minas responderam ao questionário. Entre os entrevistados, 67,6\% estão na faixa etária de 18 a 23 anos e $56,9 \%$ estão cursando entre o $7^{\circ}$ e $10^{\circ}$ período.

Entre os participantes, 44,1\% afirmaram já ter cometido plágio em relatórios, seminários ou trabalhos durante sua trajetória universitária, mesmo sabendo o quão prejudicial é o ato de plagiar e cientes da gravidade de tal atitude. Esse resultado evidencia certa naturalização desse comportamento por parte de alguns alunos, potencializado, muitas vezes, por uma sensação de impunidade.

Barbastefano e Souza (2007) realizaram um levantamento baseado na consulta de 79 alunos do curso de Engenharia de Produção do Centro Federal de Educação Tecnológica do Rio de Janeiro (CEFET-RJ), dos quais 50\% dos entrevistados não caracterizam o plágio como crime, como considera a Legislação Brasileira, explicitando a falta de conhecimento e de importância dada pelos discentes ao tema, visto que o plágio é uma infração prevista em lei como crime de violação aos direitos autorais e passível de multa e até detenção. Segundo a mesma pesquisa, 29,4\% dos consultados julgaram ser plausível a hipótese de fraudar ou plagiar atividades avaliativas com o intuito de alcançarem melhores resultados. Em outras palavras, os estudantes consideram admissível o plágio voluntário, aquele relacionado à falta de preparo, de domínio dos conteúdos acadêmicos e que se tornou hábito entre os alunos que veem essa prática como um caminho mais fácil para cumprir suas obrigações.

Souza e Reinert (2010) descrevem a insatisfação dos estudantes com relação à instituição como outra causa significativa para a realização do plágio, motivado, nesses casos, pelo 
descontentamento ou desinteresse pelo modelo de ensino, pelos conteúdos abordados e pelos métodos utilizados. Dessa forma, despertar o interesse dos alunos pelos conteúdos abordados apresentando novas formas de ensino, metodologias alternativas e mais atividades práticas pode potencializar o empenho e, consequentemente, a absorção do conteúdo das disciplinas.

A falta de diálogo entre instituição e aluno também contribui para a desinformação dos estudantes a respeito das normas nas universidades. Tal cenário evidencia a necessidade da elaboração de normas específicas sobre plágio, seguida de intensa divulgação e conscientização dos discentes por parte da UFOP, além da aplicação efetiva de medidas corretivas para intensificar a luta contra os maus hábitos acadêmicos.

\subsection{Medidas preventivas}

Embora a aplicação de medidas corretivas seja fundamental para o controle do plágio nas universidades, medidas preventivas são ainda mais importantes, visto que a conscientização dos alunos evita a ocorrência da cópia e, consequentemente, dispensa a aplicação de punições. De acordo com o presidente do colegiado de Engenharia de Minas da UFOP, atualmente, cada professor, dentro de sua disciplina, tem a responsabilidade de trabalhar com seus alunos a prevenção do plágio em trabalhos, seminários, relatórios e publicações. Dessa maneira, cabe ao professor de cada disciplina a responsabilidade de instruir, cobrar e advertir o seu aluno, como também é de sua responsabilidade seguir com um processo administrativo junto ao colegiado do curso quando se detecta um caso de plágio, salvo quando há denúncias de terceiros - nesses casos, a responsabilidade é do colegiado e da comissão do processo disciplinar.

No Brasil, a inclusão da disciplina Metodologia Científica nas matrizes curriculares dos cursos superiores foi sugerida pelas Diretrizes Curriculares Nacionais e acatada pelo curso de Engenharia de Minas da UFOP no ano de 2013. Foi um passo importante na prevenção do plágio acadêmico, visto que prática da escrita científica, a utilização de citações e referências e a aplicação das normas da ABNT, entre outros conteúdos abordados na disciplina, preparam os alunos para realizar trabalhos acadêmicos. Aires e Pillati (2017) discorrem, no entanto, que apenas a disciplina não é suficiente para abordar toda a problemática do plágio. Nesse sentido, surge a necessidade de apoio e manutenção constantes por parte das instituições de ensino com relação ao tema, trabalhando com palestras, workshops e divulgação das normas institucionais nos sites das universidades. Além disso, é fundamental que os professores cobrem e fiscalizem em todas as disciplinas a realização de atividades que sigam as normas de escrita científica, lembrando constantemente o aluno sobre o quão grave é o plágio e quais as punições para quem o comete.

Instituições renomadas, como a Universidade de Harvard, mostram o quanto é importante trabalhar a ética em relação à autenticidade de dados em produções científicas e atividades acadêmicas. A partir de seu código de honra, os alunos dessa universidade fazem um juramento ao ingressarem no início de cada período letivo ou até mesmo antes de uma prova, no qual prometem não plagiar ou colar. Caso o juramento seja descumprido, o aluno tem a ciência de que poderá ser desligado da universidade, reafirmando constantemente a importância da retidão na vida pessoal e acadêmica desde as mais simples atitudes.

$\mathrm{Na}$ pesquisa com os discentes da UFOP, foram identificadas as principais causas do índice de plágio acadêmico. Baseado nas respostas dos consultados, a falta de domínio sobre o tema das atividades, a insegurança dos alunos e o modelo de avaliação empregado pelas universidades foram as causas mais listadas, como mostra a Figura 1. 
Figura 1 - Principais causas que influenciam os alunos a recorrem ao plágio

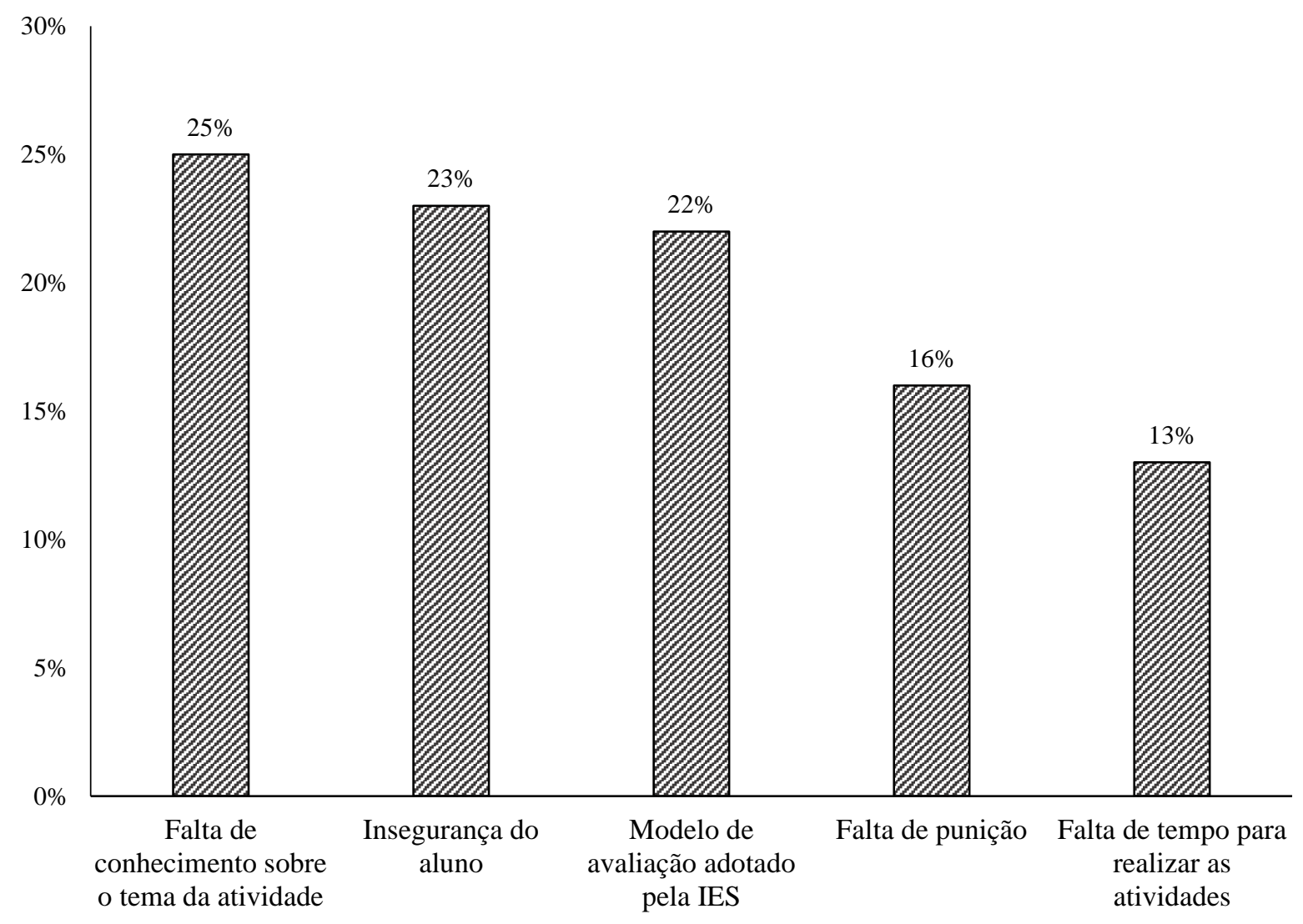

Fonte: Elaboração própria

As duas principais razões pelas quais os estudantes cometem plágio estão relacionadas, sobretudo, a questões subjetivas, como não acreditar em seu potencial, seja por causa do sentimento de ansiedade comum entre os alunos da graduação ou pela insegurança gerada no meio acadêmico devido à competição por bons resultados. Dessa forma, os estudantes recorrem ao plágio para suprir a necessidade diante de uma avaliação ou de um trabalho, buscando a garantia do bom resultado, embora seja ilegal.

A insatisfação com o modelo de avaliação das IES pode ser confirmada também pelas respostas discursivas fornecidas pelos alunos participantes da pesquisa, agrupadas pelo método DSC. O grupo das respostas sintetizou o discurso da maioria dos discentes, que consideram o plágio válido em duas situações: quando o método de avaliação exige a reprodução fiel do conteúdo e quando não há a devida assistência do professor durante a escrita do trabalho.

Entretanto, é possível traçar medidas para combater ou amenizar a prática de plágio, atualmente enraizada na cultura acadêmica. Uma alternativa seria a adoção de ações já consolidadas em certas universidades, outra medida que poderia ser eficaz é a aplicação de metodologias desenvolvidas por especialistas da área, por exemplo, a teoria de Krokoscz (2011), que dividiu as ações necessárias para o controle da prática de plágio em quatro pilares, consistindo em medidas institucionais, preventivas, diagnósticas e corretivas, apresentadas na Tabela 2. 
Tabela 2 - Abordagens adotadas por algumas universidades no mundo em relação ao plágio

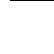

$\begin{array}{cccc}\text { Medidas Institucionais } & \begin{array}{c}\text { Medidas } \\ \text { Preventivas }\end{array} & \begin{array}{c}\text { Medidas } \\ \text { Diagnósticas }\end{array} & \begin{array}{c}\text { Medidas } \\ \text { Corretivas }\end{array}\end{array}$

“Hotsite” Institucional

Orientação

Software

Descrição do

Plágio

Guias manuais e documentos

oficiais sobre o assunto

Capacitação

Penalização

Fonte: Adaptado de Krokoscz (2011)

As medidas institucionais caracterizam-se como aquelas tomadas pela instituição com o intuito de disseminar o conhecimento sobre o conceito de plágio e os seus prejuízos, além dos crimes que o acompanham. As medidas preventivas atuam juntamente às institucionais e consistem em ações de capacitação dos professores e de instrução dos alunos para evitar o ato do plágio. As medidas diagnósticas estão relacionadas ao uso de softwares, como o CopySpider, Turnitin, iThenticate, Plagiarism Detector e Plagius, para facilitar o monitoramento dos trabalhos acadêmicos, diagnosticando de forma mais rápida e efetiva a ocorrência de qualquer tipo de plágio, vide a grande dificuldade em verificar manualmente os trabalhos realizados pelos alunos. Por fim, as medidas corretivas, que representam a atuação direta de controle sobre o ato do plágio, como a apresentação de códigos de ética e boa conduta e, em último caso, a penalização ao discente que cometeu plágio.
\end{abstract}

\title{
3.4 Conduta da UFOP frente ao plágio
}

A Pró-reitora de Graduação da UFOP delega aos colegiados de cada curso a responsabilidade de conscientizar e fiscalizar os alunos a respeito do plágio, ao mesmo tempo em que reforça a existência da Resolução CUNI n ${ }^{\circ}$ 2060, criada em 2018, a qual regulamenta o Código de Convivência Discente, abrangente a todos os alunos matriculados na instituição, tanto graduandos como pós-graduandos. O Artigo $3^{\circ}$ do Capítulo II, inciso VIII dessa Resolução orienta "Não cometer qualquer forma de plágio" e o Artigo $4^{\circ}$ do Capítulo III inciso XIII pró́be "Valer-se de meio ilícito ou de modo ímprobo na realização das atividades escolares", evidenciando a postura da Instituição contra qualquer ato de cópia ou apropriação irregular de informações.

O Capítulo IV da Resolução apresenta as cinco sanções impostas para o descumprimento do Capítulo II e III. Tais medidas têm como objetivo punir os alunos infratores, que podem ser penalizados de acordo com a interpretação da comissão do processo disciplinar, conforme o Art. 175 do Regimento Geral da Universidade Federal de Ouro Preto.

a) advertência oral;

b) repreensão escrita;

c) suspensão de até 30 dias letivos; 
d) suspensão de até 90 dias letivos;

e) desligamento.

De acordo com esse documento, o aluno reincidente será advertido com punições mais severas, ou seja, caso o discente venha a cometer o plágio somente uma única vez, a universidade o advertirá com o inciso 1 "a" e, se o aluno não reincidir até o final do curso, será considerado sem efeito o registro da sanção. Porém, em caso de insistência na infração prevista, o aluno será acometido pelo inciso 2 "b", depois 3 "c" e assim por diante, salvo o inciso 5 "e", no qual a comissão do processo disciplinar pode examinar os omissos e aplicá-lo a qualquer instante.

Nesta pesquisa, foi questionado aos docentes e discentes sobre o conhecimento do Código de Convivência Discente, presente na Resolução CUNI 2060. Analisando os dados, verificouse que a maioria dos alunos $(85,3 \%)$ e dos professores $(70 \%)$ desconhecem a norma, o que contribui para a falta de punição em caso de plágio. Sendo assim, faz-se necessário o esclarecimento eficaz aos docentes sobre as providências legais a serem tomadas ao se depararem com um trabalho plagiado, assim como é indispensável a aplicação das medidas, por parte dos docentes, rigorosamente de acordo com as normas da instituição.

A falta de punição para os alunos que cometem o plágio é evidenciada pelas respostas do questionário, no qual consta que somente $30 \%$ dos professores aplicam nota mínima ao aluno que comete o plágio e os outros $70 \%$ apenas os orientam. Baseando-se no elevado número de docentes que desconhecem o código de conduta, pode-se afirmar que a falta de instrução adequada ocasiona medidas inadequadas, gerando a sensação de impunidade e a manutenção do elevado índice de plágio na instituição.

\section{CONCLUSÃO}

Analisando o contexto histórico, é possível observar a disseminação do plágio com a facilidade de acesso a informações. Nessa perspectiva, pode-se perceber que o modelo de ensino e de proteção de conteúdo não se desenvolveu com a mesma velocidade que a globalização, contribuindo para o aumento significativo nas práticas de plágio, que, embora sempre praticado, nunca esteve tão comum.

Baseando nas respostas de discentes e docentes da UFOP após aplicação do questionário, notou-se que a maioria dos alunos já plagiaram, seja de forma intencional ou não. Esse cenário, associado ao sentimento de impunidade por parte dos alunos promove a necessidade de ações de controle do plágio na instituição, como a elaboração de resoluções referentes à prática do plágio de forma mais clara, específica e melhor divulgada.

Outro ponto importante é a necessidade de investir no aprimoramento dos métodos de escrita e pesquisa no ensino nacional. Foi observada uma defasagem significativa na capacidade de expressar e de pesquisar dos alunos de graduação, proveniente do ensino básico e resultando, então, na dificuldade dos mesmos em expor suas ideias e absorver conteúdo. Essas dificuldades acarretam na insegurança do aluno ao realizar qualquer atividade acadêmica, induzindo-os a recorrer ao plágio como forma de garantia de bons resultados. Dessa forma, o investimento na capacitação e no preparo dos estudantes é de fundamental importância para a redução do plágio no âmbito acadêmico.

Na graduação, o processo de conscientização dos alunos quanto ao plágio precisa ser mais eficiente e dinâmico. A utilização de softwares de diagnóstico de plágio, assim como a determinação de medidas preventivas e corretivas que mostrem aos graduandos a gravidade e 
as consequências dessa prática para si, para terceiros e para a sociedade como um todo certamente reduzirá o índice de plágio por parte dos alunos.

Segundo a pesquisa realizada, a maioria dos professores não aplicam medidas corretivas aos alunos plagiadores. Além disso, o fato de os alunos e os professores consultados desconhecerem o Código de Conduta Discente da UFOP precisa ser revertido urgentemente, visto que essa resolução consiste no principal documento diretor de combate ao plágio da instituição.

\section{Agradecimentos}

Os autores agradecem à Universidade Federal de Ouro Preto e ao CNPq.

\section{REFERÊNCIAS}

AIRES, J. P.; PILATTI, L. A. Medidas de combate ao plágio, adotadas por instituições de ensino superior: uma análise da efetividade das ações na área de Ensino. REBECT. Ponta Grossa, v.10 n.3 p.163-184, set./dez., 2017.

BARBASTEFANO, R. G.; SOUZA C. G. Percepção do conceito de plágio acadêmico entre alunos de engenharia de produção e ações para sua redução. Disponível em: https://www.researchgate.net/publication/274282272_Percepcao_do_conceito_de_plagio_aca demico_entre_alunos_de_engenharia_de_producao_e_acoes_para_sua_reducao. Acesso em: 15 maio 2020.

CÓDIGO DE CONVIVÊNCIA DISCENTE. CUNI2060, Disponível em: https://www.soc.ufop.br/public/files/RESOLUCAO_CUNI_2060_ANEXO_0.pdf. Acesso em 17 maio 2020.

COSTA, R. M. C. D. Plágio acadêmico: a responsabilidade das associações científicas. Intercom - RBCC. São Paulo, v. 39, n. 3, p. 187-200, set./dez. 2016. Disponível em: https://www.scielo.br/pdf/interc/v39n3/1809-5844-interc-39-3-0187.pdf. Acesso em: 25 jun. 2020.

DIAS, W. T.; EISENBERG, Z. Reflexões sobre ética, plágio e pesquisa na escola. Disponível em: https://files.cercomp.ufg.br/weby/up/693/o/TR03.PDF. Acesso em: 22 jun. 2020.

FAPESP - Código de boas práticas científicas. Disponível em: http://www.fapesp.br/boaspraticas/codigo_fapesp0911.pdf. Acesso em: 20 jun. 2020.

GIMENEZ, A. N. M. O direito do autor e o autoplágio: entre o lícito, ilícito e o antiético. Disponível em: https://jus.com.br/artigos/38311/o-direito-do-autor-e-o-autoplagio-entre-olicito-ilicito-e-o-antietico. Acesso em: 18 jun. 2020.

GREGO, M. Conteúdo digital dobra a cada dois anos no mundo. Disponível em: https://exame.com/tecnologia/conteudo-digital-dobra-a-cada-dois-anos-no-mundo/. Acesso em: 22 jun. 2020.

KROKOSCZ, M. Abordagem do plágio nas três melhores universidades de cada um dos cinco continentes e do Brasil. Disponível em: https://www.scielo.br/pdf/rbedu/v16n48/v16n48a11.pdf. Acesso em: 22 maio 2020. 
SOUZA, S. A.; REINERT, J. N. Avaliação de um curso de ensino superior através da satisfação/insatisfação discente. Disponível em: https://www.scielo.br/scielo.php?pid=S141440772010000100009\&script=sci_arttext\&tlng=pt \#fig1. Acesso em: 19 maio 2020.

\title{
PLAGIARISM IN THE VIEW OF STUDENTS AND TEACHERS OF THE MINING ENGINEERING COURSE AT UFOP
}

\begin{abstract}
The objective of this work was to evaluate the conduct and discernment of students and teachers of the Department of Mining Engineering of Federal University of Ouro Preto in the face of plagiarism. The methods used included a digital research carried out with the participation of the student and faculty of the course. The results allowed the understanding of the recurrent practice of plagiarism by the students, mainly due to the lack of knowledge of the institutional norms, by the discontent with teaching methods, and by the insecurity for performing activities on their own. It was possible to observe that impunity with those who perform plagiarism, associated with the lack of knowledge of the norms by teachers, and the scarcity of awareness measures by the University promotes the practice of plagiarism. As a way of controlling this practice, measures were proposed such as the orientation of students and teachers and discussions regarding plagiarism in all disciplines. In addition, is necessary the strict application of the regulations established by the Code of Student Coexistence by all teachers, as well as a greater dissemination of the norms by the university.
\end{abstract}

Keywords: Plagiarism. Academic formation. Education. Scientific writing. 